\title{
LA Regla Agustina: AMOR Como APETito. Breve HISTORIA DEL ABANDONO DEL ESPÍRITU AGUSTINO POR LOS HERMANOS PREDICADORES EN CHIAPAS
}

\section{The Augustinian Rule: Love as Appetite. Brief History of the Abandonment of the Augustinian Spirit by the Friars Preachers in Chiapas}

\section{Adriana Di Giacomo ${ }^{1}$}

Resumen: Agustín de Hipona funda todos sus estudios teológicos en el amor. La regla agustina es un código de normas adoptado en diferentes contextos monásticos y también por los dominicos desde la fundación de la orden. Esta regla motiva hacia el amor caritativo y la espiritualidad de la vida comunitaria, compuesta por vida contemplativa y vida activa.

El presente artículo propone analizar el espíritu agustino de los hermanos predicadores durante el trabajo de evangelización en Chiapas, y mostrar, a partir de la definición agustina del amor, entendido como appetitus, un desvío de la espiritualidad de la orden hacia la codicia, el falso amor que se agarra al mundo.

Palabras clave: antropología de la religión, dominicos, evangelización, poder.

\footnotetext{
${ }^{1}$ Maestra en disciplinas de las artes de la música y del espectáculo, línea de especialización en Etnomusicología, Facultad de Letras y Filosofía de Universidad de Roma Tre, Italia. Maestrante en el Programa de Posgrado en Música, campo de conocimiento en Etnomusicología de la Universidad Nacional Autónoma de México. Correo electrónico: adrianadigiacomo@libero.it

Fecha de recepción: 0710 14; Fecha de aceptación: 110315.
} 
Abstract: All of Augustine of Hippo's theological studies are founded in love. Augustinian rule is a code of norms adopted in different monastic contexts and by the Dominicans ever since the order was founded. This rule motivates towards charity love and community life spirituality, composed of contemplative life and active life.

This article proposes an analysis of the Augustinian spirit of the Friars Preachers during the work of evangelization in Chiapas, and it shows, from the Augustinian definition of love, understood as appetitus, a deviation of the Dominican spirituality to cupidity, the false love that involves the world.

Keywords: anthropology of religion, dominicans, evangelization, power.

\section{Génesis de la orden de los hermanos predicadores}

Contemplari et contemplata aliis tradere, ${ }^{2}$ contemplar y dar a otros lo contemplado: ésta es en síntesis la regla de los hermanos predicadores, conocidos como dominicos.

La Ordo Fratrum Praedicatorum fue fundada en Toulouse por Domingo de Guzmán con el fin de contrarrestar la herejía de los albigenses en plena Baja Edad Media. En 1216 fue confirmada por el Papa Honorius III en las bulas Religiosam vitam y Nos attendentes, con la aprobación de una serie de privilegios como el derecho a predicar y a escuchar confesiones en cualquier lugar sin tener autorización por parte del obispo de la diócesis local. La finalidad de la orden de los hermanos predicadores se expresa a partir de las palabras del Papa Honorio III, que en la carta a Santo Domingo, afirma: "Aquel que sin cesar fecunda su

\footnotetext{
${ }^{2}$ Tomás de Aquino, Summa theologiae, libro II-II, q.188, a.7. "La vida contemplativa en absoluto es superior a la vida activa, que se aplica a actos corporales. No obstante, la vida activa, por la que alguien comunica a los demás, mediante la predicación y la enseńanza, lo que antes ha contemplado, es más perfecta que la vida exclusivamente contemplativa, porque aquella vida presupone la abundancia de la contemplación. Y por ese motivo eligió Cristo tal género de vida" (Tomás de Aquino, Summa theologiae, libro III, q.40, a.1).
} 
Iglesia con nuevos hijos, queriendo asemejar los tiempos actuales a los primitivos y propagar la fe católica, os inspiró el piadoso deseo de abrazar la pobreza y profesar la vida regular para dedicaros a la predicación de la palabra de Dios, propagando por el mundo el nombre de nuestro Señor Jesucristo". ${ }^{3}$ Entre las disposiciones conciliares lateranenses, ${ }^{4}$ recogidas en 71 cánones, está también la imposición de carácter disciplinar a las órdenes religiosas de adoptar una de las reglas ya existentes. Los dominicos eligieron la regla de San Agustín.

Lo que propongo a continuación es una lectura comentada de la regla agustina, sobre la cual se erige la regla de los frailes predicadores, útil para entender el origen de su espiritualidad, la influencia en su trabajo de evangelización y para rastrear las congruencias e incongruencias del apostolado dominicano en Chiapas a partir de su misma regla.

\section{La regla agustina}

"Hermanos carísimos: Ante todo, amemos a Dios, y después también al prójimo, porque estos son los mandamientos principales que nos han sido dados" (Hipona, 1995: 560). Eso es el íncipit de la regla agustina, llamada por los agustinólogos Praeceptum o Regula tertia o Regula ad servos Dei, ${ }^{5}$ Regula de los servidores de Dios. La esencialidad fue la característica que hizo de la regla agustina una regla versátil en diferentes contextos monásticos. Unos de éstos fue la orden dominica en la que los frailes construyen su identidad religiosa conformándose a esta regla, la cual consta de un prólogo y de ocho capítulos.

El prólogo es esencialmente una repetición — recordación- de lo que estaba ya en el Antiguo Testamento: "amarás a tu prójimo como a ti mismo" (Levítico 19: 18) conectado con el nuevo mandamiento de la ley de Jesús de Nazaret "les doy un mandamiento nuevo: que se amen unos a otros; como yo los he amado" (Jn 13, 34). Como yo los he amado es la novedad del mandamiento, es decir, la práctica del amor al

3 Honorio III, carta a Santo Domingo, fecha 18 de enero de 1221 en $\mathrm{MOPH}$ (Monumenta Ordinis fr. Praedicatorum Historica) XXV, p. 144.

${ }^{4}$ El Concilio de Letrán IV fue convocado bajo el Papa Inocencio III en 1215.

5 Para la escritura de este ensayo me basé en la versión de la regla de San Agustín publicada por Teodoro C. Madrid en Obras completas de San Agustín XL. 
prójimo se hace posible sólo después del perfecto amor de Cristo, sólo después del amor de Dios es posible amar al mismo Dios y al prójimo. La imitación de Cristo en el amor permite amar en un círculo perfecto de amor que regresa hacia Dios y desde Dios por medio de sus criaturas hacia el prójimo.

Dante Alighieri en el V Canto del Infierno de La Divina Comedia escribió uno de los versos más célebres de la literatura italiana: "Amor, ch'a nullo amato amar perdona", Amor, que a nadie amado, amar perdona (Infierno: V, 103). El amor que obliga a quien es amado a reamar; es un verso que habla de la existencia infinita y eterna del amor, de su forma circular. El contenido ético cristiano de este verso nos ayuda a entender el concepto teológico agustino del amor descendente de Dios hacia sus criaturas. El amor desde Dios llega al hombre y desde el hombre regresa hacia Dios y al prójimo. El hombre es amado por Dios; recibiendo este don está obligado por el amor a reamar.

El ser humano, imagen de su creador, es conductor del movimiento circular del amor; no puede amar al prójimo si antes no ama a Dios, un Dios que, a su vez, se hace visible a los hombres a través del amor de los unos a los otros. El amor ágape es según la teoría cristiana la virtud teologal superior a todas las virtudes teologales. Hablar de amor en la teología cristiana equivale a hablar de caridad. Por esta razón en los textos bíblicos las palabras caridad y amor son sinónimas. En el Comentario a la primera carta de San Juan, el obispo de Hipona nos introduce a otra analogía: Dios es Amor, el amor no entendido como alta virtud o como un componente de Dios, sino como el Ser mismo. La manifestación del Dios-Ágape es el amor universal para los hermanos. Amigos y enemigos, pobres y poderosos, personas lejanas y cercanas, a todos toca el Amor Caritas en una universalidad inclusiva.

Si leemos la misión dominica a la luz de esta parte de la regla agustina, entenderemos cuán importante es el amor a Dios y el amor social, aquel amor que reconoce en los vestidos del prójimo el vestido de Dios. El mismo amor a Dios es amor social, y su negación sería reducir el amor a aquel dirigido exclusivamente a sí mismo. La orden dominica sería, en la génesis de su regla, una misión de vida guiada por el amor/caridad, identificada en la carta paulina como amor 
"paciente que muestra comprensión, que no tiene celos, no aparenta ni se infla. No actúa con bajeza ni busca su propio interés, no se deja llevar por la ira y olvida lo malo. No se alegra de lo injusto, sino que se goza en la verdad. Perdura a pesar de todo, lo cree todo, lo espera todo y lo soporta todo" (1 Co 13, 4-7).

De caridad tenían que vivir los hermanos de la orden de los predicadores. Primero Santo Domingo vistió de pobreza su vida, imponiendo esta misma conducta a sus frailes: "Les impuso usar vestidos pobres y no llevar nunca consigo dinero en los viajes, sino vivir en todas partes de limosnas. Hizo que esto se introdujera en su regla, o sea en las constituciones" (ACB, tg. VII, n. 3). ${ }^{6}$

Profesando los votos de pobreza, castidad y obediencia, regidos por la antigua regla que era impuesta a todos los miembros de cualquier orden mendicante, los dominicos renunciaban a tener todo tipo de posesión material, poner todo al servicio y disposición de la comunidad y vivir sólo de la caridad. Así está escrito en el primer capítulo de la regla agustina, que regula fin y fundamento de la vida común (Hipona, 1995). Pensada como una forma de vivir en comunión con Cristo y de ser un sólo cuerpo, unánime. Cristo llama a una vida en comunidad, llama a formar los miembros de un único cuerpo, la iglesia, que es Él mismo, "porque así como, siendo el cuerpo uno, tiene muchos miembros, y todos los miembros del cuerpo, con ser muchos, son un cuerpo único, así es también Cristo" (1 Co 12, 12). La comunidad es llamada a conformarse y ser el cuerpo de Cristo. "Para que cada convento sea una verdadera comunidad, los frailes se deberán tratar y acoger unos a otros fraternalmente como miembros de un mismo cuerpo, diferentes ciertamente por su propia índole o por sus cargos, pero todos iguales por el vínculo de la caridad y de la profesión" (LCO n. $4, \mathrm{I})$.

Con los votos de pobreza, castidad y obediencia los religiosos pertenecientes a las órdenes mendicantes querían imitar y adherir a la vida de Cristo, conformándose a la Iglesia pobre de los primeros evangelistas. El segundo capítulo de la regla de San Agustín impone la oración en la vida contemplativa y apostólica de los frailes: "sed

\footnotetext{
${ }^{6}$ ACB, citado en González Fuente, Antolín, El Carisma de la vida dominicana (1994: 218).
} 
constantes en la oración” (Hipona, 1995: 566). La oración entendida como ejercicio espiritual se convierte en lugar íntimo de encuentro con la divinidad. La vida contemplativa de la orden dominica se construye de alabanza y del estudio de la sagrada escritura.

En el De Trinitate, Agustín ofrece una reflexión del hombre concebido por la creación de Dios con razón, voluntad y libertad. En una recíproca conexión estas tres facultades forman una unidad, en clara referencia a la imagen de la trinidad divina. El potencial de buscar y de amar el Sumo Bien es congénito en el hombre, pero tener el potencial no significa que el hombre busca y ama a Dios. El hombre también podría decidir dirigir su razón, voluntad y libertad hacia el pecado. El ministerio de la voluntad es la elección, la cual emerge como fuerza de amor. A la voluntad le es dado el mandato de dirigir la razón hacia la libertad plena que es Dios. Un hombre es plenamente libre sólo cuando entre el bien y el mal elije el bien, para hacer eso es necesaria una vida contemplativa que pueda permitir al hombre estar sub lege y sub gratia — bajo la ley y bajo la gracia.

Pilar no sólo de la orden dominica sino de toda la Iglesia católica, el teólogo y filósofo Tomás de Aquino explica el significado y el valor de la vida contemplativa como el signo más eficaz de la caridad. El entendimiento de la verdad divina es el fin último de la vida contemplativa:

La vida contemplativa, aunque consiste esencialmente en el entendimiento, tiene su principio en la voluntad, en cuanto que el amor de Dios impulsa a la contemplación. Y dado que el fin corresponde al principio, de ahí que el término y el fin de la vida contemplativa haya que buscarlo en la voluntad, en cuanto que se encuentra deleite en la visión del objeto amado, y el deleite del objeto visto enciende más ese amor. Por eso dice San Gregorio, en Super Ezech., que, cuando se ha visto a quien se ama, se enciende más ese amor. Y ésta es la perfección última de la vida contemplativa: que no sólo se ve sino que también se ama la verdad divina (ST, IIII, q. 180, a.7). 
¿Cómo conciliar la misión evangelizadora de la orden dominica, que es más bien considerada vida activa, una actividad exterior, dirigida hacia un "otro" externo, con la vida contemplativa que en la alabanza y en el estudio de la palabra dirigida hacia la verdad, impone un silencio místico, un reposo de los movimientos exteriores?

En palabra de Santo Tomás: "una Orden fundada para la contemplación y para transmitir a otros lo contemplado mediante la enseñanza y la predicación que aquella que fue fundada únicamente para la contemplación” (ST, II-II, q.188, a.7).

Santo Tomás considera que no hay una interrupción completa y consecuente entre vida contemplativa y vida activa. Él encuentra un equilibrio eficaz en el ministerio de la palabra, es decir, en la predicación, que no es nada más la expansión, actividad externa de lo contemplado. ${ }^{7}$ En el ejercicio de las virtudes morales de los frailes dominicos, alabar a Dios es conocerlo; también tiene importancia relevante la lectura y el estudio contemplativo de la sagrada escritura. Ambos son alimentos de la vida apostólica, de la vida activa de la predicación, verdadera misión de la orden dominica. "La vida propia de la Orden; una vida apostólica en sentido pleno, en la cual la predicación y la enseñanza deben proceder de la abundancia de la contemplación". ${ }^{8}$

En la predicación, entendida como enseñanza de la verdad divina revelada con la contemplación, los frailes dominicos realizan una síntesis entre el trabajo misionero y su vida intelectual. La orden monástica, manteniendo en la enseñanza/predicación su tradición en el estudio de la palabra y en la contemplación, se vuelve Alma Máter —alma madre- para la conversión de los "otros” y para la defensa de la fe.

\footnotetext{
7 Tras el interés de Santo Tomás por la relación de la vida contemplativa con la vida activa se lee la tensión veinteñal del siglo XIII entre los maestros seculares y las órdenes de los franciscanos y dominicos. Los privilegios concedidos por los pontífices a las órdenes mendicantes minaban el tradicional sistema eclesiástico que ejercía su poder con base en el número de almas que les eran encargadas.

Para profundizar en el argumento, leer D.L. Douie, The conflict between the seculars and the mendicants at the University of Paris in the thirteenth century (1954).

${ }^{8}$ Liber const. et ordin., n. $1 \$ I V$.
} 
Siguiendo la lectura de la regla, el tercero, cuarto y quinto capítulo son un verdadero manual de vida práctica para las órdenes (Hipona, 1995). Profundo conocedor del ser humano, Agustín da advertencias sobre las pasiones naturales en las cuales pueden caer los frailes, y exige la práctica de una vida moderada, la observancia del ayuno y la mortificación corporal como unos entre otros métodos para disciplinar y someter tanto el espíritu como la carne. Se trata de una disciplina dual de espíritu y de carne - que implica sobre todo la castidad, tema central en todas las órdenes mendicantes. La regla nos dice que sin castidad de cuerpo y pensamiento se abandona el estado de pureza a que aspira la vida consagrada. En el pensamiento de Agustín, el ser humano no es un ser de absoluto bien, ésta es la esencia de Dios. Agustín, defendiendo la corporeidad del hombre y su unión sustancial con el alma, nos habla de mixtura — de alma y de cuerpo-. Merece la pena citar un fragmento del cap. XXIV del último libro que compone la obra agustina La Ciudad de Dios, verdadero poema de exaltación de la belleza plena del cuerpo humano. Agustín escribe:

Pues aun en el mismo cuerpo, aunque en ser mortal, le tengamos común con las bestias y sea más débil que muchas de ellas, ¿cuán grande hondad de Dios se descubre, cuán grande providencia campea del Sumo Criador? ¿Acaso los lugares propios de los sentidos, y los demás miembros, no están tan ordenados y bien organizados en él; la misma figura y la constitución de todo el cuerpo no está modificada de manera que muestra haberse hecho para el ministerio de un alma racional? Porque no como a los animales irracionales, qué van inclinados á la tierra, crió Dios al hombre, sino que la forma del cuerpo, elevada al cielo, le está diciendo que atienda y procure las cosas celestiales (Hipona, 1994: XXII, 24).

En la concepción agustina el hombre, creado a semejanza de Dios, es al mismo tiempo bueno por ser criatura de Dios, por gozar y responder a su amor, es decir, el cuerpo del ser humano sumiso y orientado hacia Dios se entiende como un cuerpo sacralizado; pero también es malo, porque la naturaleza humana es corruptible con el pecado, entendido 
como privación del Sumo Bien. La pretensión de la regla agustina es, sin duda alguna, elogiar un modelo de vida virtuosa que crece y se fortalece en la vida en común a imitación de la primera comunidad cristiana: "Y la multitud de los que habían creído era de un corazón y un alma; y ninguno decía ser suyo propio nada de lo que poseía, sino que tenían todas las cosas en común [...]. Así que no había entre ellos ningún necesitado; porque todos los que poseían heredades o casas, las vendían, y traían el precio de lo vendido, y lo ponían a los pies de los apóstoles; y se repartía a cada uno según su necesidad" (Hechos 4, 32-35).

Un comportamiento íntegro se manifiesta no solamente en el empleo de las cosas necesarias y en la cura de las cosas comunes, sino también en el cuidado de la palabra y el perdón de las ofensas, como se encuentra descrito en el sexto capítulo de la regla: "quien ofende a otro con injuria, insulto o hasta delito grave, acuérdese de remediar cuanto antes lo que hizo, y el ofendido de perdonar sin más" (Hipona, 1995: 584).

Los tres votos de la vida monástica son fácilmente reconocibles en el texto agustino. Se habló de la pobreza, de la castidad, y falta mencionar la obediencia. Se establecen dos personajes a los cuales se tiene que obedecer, al Superior Local y al Superior Mayor. La obediencia que se pide es la misma que se da a un padre. Por medio de la obediencia a la regla, los frailes de la familia dominica se consagran a Dios. Para cumplir con ella es necesaria la mortificación que eleva a la condición de siervo, "así como el Hijo del Hombre no vino para ser servido, sino para servir y para dar su vida en rescate por muchos" (Mateo 20, 28).

La regla agustina es un código de normas que aclara y orienta la vida comunitaria, es una doctrina teológica esencial, pero al mismo tiempo concreta, capaz de armonizar en la caridad/amor las promesas de pobreza, castidad y obediencia. En otras palabras, fue la más compatible, y por esta razón la orden de los frailes predicadores la adoptó. En ella vieron la síntesis de la primera comunidad cristiana, la génesis de la vida dominica construida sobre el rezo, la contemplación, el estudio, la vida comunitaria, los votos religiosos llamados a cumplir, la búsqueda de la verdad, la predicación, el trabajo de evangelización. 


\section{Rápido trazo histórico}

Después de su confirmación los frailes predicadores empezaron a ramificarse en toda Europa, privilegiando la elección de ciudades donde surgieron las primeras universidades: París, Boloña, Salamanca. Establecer conventos en las ciudades permitió a los dominicos desempeñar un papel de control de la creciente población urbana y poder usar su rigurosa preparación teológica y bíblica como arma para objetar las doctrinas heréticas, evangelizar y ganar feligreses. Sobre todo, la orden dominica en Europa se volvió conexión entre la Iglesia secular y los gobiernos locales.

Desde su fundación, la historia de la Iglesia está llena de herejías y de cismas. Herejía, del griego áiresis, significa "elección" de un nuevo camino, vía diferente de la que profesa la Iglesia; por cisma se entiende más bien "separación", sin que esta separación aporte sustanciales cambios en la doctrina o en los dogmas ${ }^{9}$ de la Iglesia católica. Los más conocidos cismas son: el que separó a la Iglesia de oriente, bizantina, de la Iglesia de occidente que quedó fiel a Roma (Cisma de Oriente 1054); y el Cisma de Occidente, con la presencia por cerca de cuarenta años (1378-1417) de dos papas, en algún momento también tres. Una iglesia partida en dos bloques adversarios generó nuevas confusiones y desilusiones entre los fieles.

En el siglo XIV un fuerte sentimiento anticlerical, o más bien antipapista, impregnó la sociedad del viejo mundo, conduciéndola más tarde a la tempestad luterana, que vio al principio del siglo XVI la separación de Roma de gran parte de los cristianos de la Europa centroseptentrional. Razones morales pero también políticas y económicas alimentaron la protesta antipapista. La Iglesia acumuló a lo largo de los siglos beneficios feudales concedidos por los soberanos a los clérigos, además de las numerosas propiedades, herencias recibidas por los fieles como donaciones — ofrendas_ y penitencias. Toda la Iglesia, desde el

\footnotetext{
${ }^{9}$ En la teología católica el dogma — decreto público- asume el significado de verdad de fe indiscutible e inmutable, basándose en dos elementos: la revelación y el magisterio de la Iglesia.
} 
alto clero aristócrata hasta las bajas órdenes mendicantes, conoce y se fortalece en el poder y en la riqueza, desviándose hacia un profundo deterioro espiritual y moral. ${ }^{10}$

Frente a un descontento general y ante la amenaza reformista luterana, la Iglesia respondió caminando por dos vías: la contrarreforma, que lucha contra las herejías para restaurar la unidad de la fe; ${ }^{11}$ y todavía antes que ésta, la reforma católica, una renovación interna de la misma Iglesia (Jedin, 1967). En el mismo mundo católico se manifestó la exigencia de una renovación de la Iglesia. Las órdenes religiosas advirtieron la urgencia de restaurar la disciplina y la moral dentro la Iglesia y reponerle la espiritualidad primigenia. En este contexto histórico, en esta necesidad de reforma, partieron desde el convento de San Esteban de Salamanca, la casa dominica más ilustre de España (De Vos, 2010: 10), las distintas expediciones hacia el nuevo mundo, respondiendo al sueño de aquel tiempo, de volver a una Iglesia pobre, como la de la primera comunidad.

Como sugiere Jérôme Baschet, 1492 no es una fecha que demarca y separa la Edad Media vista como oscurantista de los siglos XVI y XVII considerados Tiempos Modernos. Leyendo la Edad Media y la Edad Moderna como caras de una misma moneda, en una parte de su tesis defenderá "la idea de que la Conquista y la colonización no se deben a una sociedad europea liberada del oscurantismo y del inmovilismo medievales y ya entrada en la modernidad. Más bien son resultado de una dinámica de crecimiento y expansión, de una lenta acumulación de progresos técnicos e intelectuales, propios de los siglos medievales" (Baschet, 2009: 30).

En el imaginario de los frailes dominicos, la Nueva España fue un espacio heterotópico - por espacio real- en el cual proyectar la utopía de la comunidad ideal, la idea de un mundo alternativo. El Nuevo

\footnotetext{
${ }^{10}$ Entre las fuerzas que alimentaron la protesta religiosa está aquella de los hombres de cultura. Con tal propósito la voz de Erasmo de Rotterdam, en su Elogio de la locura de 1509, denuncia ideas y actitudes de poetas, filósofos, teólogos, religiosos y monjes, en contraste con el auténtico espíritu evangélico de los Padres de la Iglesia.

${ }^{11}$ Fue con el Concilio de Trento (1545-1563) que la iglesia quiso dar una respuesta precisa a las herejías, definiendo con autoridad la doctrina de la iglesia de Roma y promoviendo una reforma interna moral, espiritual y disciplinar.
} 
Mundo como cada espacio heterotópico fue interpretado por los frailes dominicos como contra espacio frente al Viejo Mundo, con la intención de superarlo y purificarlo (Foucault, 2008), un contra espacio donde injertar la utopía de la ciudad celeste. Un lugar "otro" donde crear una nueva comunidad liberada del sentido de muerte de las guerras y la corrupción del Viejo Mundo. La contraposición de estos espacios implica una cita de la división agustina entre dos ciudades, la terrenal que vive en la codicia y la celeste que vive en la caridad, dos ejemplos de comunidades divididas por dos amores: amor propio y amor a Dios (Civ. Dei. XIV, 28).

La ciudad terrenal, analogía del Viejo mundo, nace por el hombre lleno de sí mismo, de su desprecio por el prójimo, que es la gestación de todo tipo de mal. La ciudad celeste, analogía del Nuevo Mundo, nace por el hombre salvado gracias al amor de Dios y proyectado al próximo. El hombre cuando ama con amor caritas - fundado en Dios_-, sale del orgullo propio que le hace ver sólo a sí mismo, e inicia a fijarse en el otro (Hipona, 2002). El amor del hombre elevado hacia Dios es un amor que viene purificado por obra de Dios de la soberbia, la envidia, la ira, la pereza, la avaricia, la gula, la lujuria, y por eso es un amor horizontal al prójimo. El Nuevo Mundo, visto con los ojos de los frailes dominicos, parece haber sido tierra de imaginación y de deseo, una tierra lejana de las pestilencias, guerras, cismas y herejías, donde el sueño utópico, de la Ciudad del Sol, ${ }^{12}$ encuentra su esperanza.

Según el cronista dominico fray Francisco Ximénez, en su Historia de la Provincia de San Vicente de Chiapa y Guatemala, los dominicos arriban a Chiapas el 12 de marzo de 1545 sustituyendo prácticamente a los mercedarios, que llegaron a Ciudad Real en 1537 (Ruz, 1992: 107) sin desempeñar casi nunca el papel evangelizador, monopolio de los dominicos por lo menos hasta la llegada, en la década del 1570 (Viqueira, 2002) de los primeros franciscanos a Ciudad Real —actual San Cristóbal de Las Casas-. En aquel tiempo el descubrimiento del

${ }^{12}$ La Città del Sole, escrita entre 1602 y 1603 por Tommaso Campanella, describe la imagen de una de las más famosas sociedades utópicas. Una ciudad ideal organizada según una forma de comunismo jerárquico, donde cada ciudadano es feliz de trabajar por el bien común y de ser gobernado por un Príncipe Sacerdote llamado Sol, imagen tradicional de Dios. 
Nuevo Mundo refuta la tesis basada en las antiguas escrituras (Salmo 19,5), ${ }^{13}$ que sostenía que la palabra de Cristo se difundió en todo el mundo como obra de los Apóstoles. Para los dominicos Chiapas era una tierra árida de predicación evangélica. Movidos por su ideal misionero del Contemplari et contemplata aliis tradere afrontaron con audacia una navegación difícil y peligrosa ${ }^{14}$ hacia una tierra que consideraban virgen.

\section{El trabajo de evangelización}

El primer verdadero trabajo evangelizador en Chiapas fue responsabilidad de los frailes de la orden dominica, los cuales realizaron, por lo menos en un primer momento, un trabajo pastoral basado en un método pacífico, es decir, convertir a los indios con la sola arma de la persuasión. La conquista pacífica fue pensada y preparada por el dominico fray Bartolomé de Las Casas.

Este fraile tiene el mérito de haber llevado consigo, desde España a Chiapas, la Leyes Nuevas, ${ }^{15}$ un corpus de disposiciones reales que ponía fin a la esclavitud de los indios y a los abusos arbitrarios existentes en el sistema de encomienda (De Vos, 1988: 67).

A su llegada, en Ciudad Real los dominicos habían entrado en hostilidad con los encomenderos y otros colonizadores, esta tensión fue sentida por ellos como una urgencia a aprender la labor de evangelización en lugares distintos, formar a los naturales en la verdadera doctrina cristiana y liberarlos de la idolatría demoniaca.

Así informa Fr. A. Remesal en Historia general de las Indias Occidentales y particular de la gobernación de Chiapa y Guatemala, (1992): "lugares hay muy populosos en donde podamos fundar conventos y salir de allí a predicar la tierra los unos cerca de los otros; y si muriese algún religioso o cayere enfermo, fácil cosa será enviar

\footnotetext{
13 “Resuena su eco por toda la tierra y su lenguaje, hasta los confines del mundo".

${ }^{14}$ Una buena parte de los frailes que salieron de Salamanca en 1544, encontraron la muerte en el mar entre las costas de Campeche y Tabasco (Viqueira 2002, De Vos 2010).

${ }^{15}$ Las Leyes y Ordenanzas recientemente hechas por su Majestad para el gobierno de las Indias y el buen trato y conservación de los indios fue promulgada por el emperador Carlos V en Barcelona el 20 de noviembre de 1542.
} 
con brevedad a otro en su lugar, antes que lo que él ha doctrinado y enseñado a los indios se les olvide y tenga lugar el demonio de volverse entre ellos". ${ }^{16}$

Para organizar el difícil trabajo misionero, los dominicos eligieron diferentes puntos estratégicos en la región. La primera elección cayó sobre la ciudad de Chiapa - Chiapa de Corzo_- "ubicada en un paso obligado del camino que unía el altiplano guatemalteco con Tabasco, Oaxaca y el centro de México" (Viqueira, 2002: 181). Más adelante se encontraba la población de Zinacantán, favorable por su cercanía a Ciudad Real y Copanaguastla en el valle meridional. En 1546, para poder ampliar la evangelización también en el área de los zoques, los predicadores se asentaron en Tecpatán (Viqueira, 2002).

En un breve lapso de tiempo, levantaron conventos ${ }^{17}$ en Zinacantán, ${ }^{18}$ Copanaguastla, Chiapa de los Indios, Tecpatán, Comitán y Ocosingo. Los conventos desde siempre fueron, para toda la orden dominica, exteriorización de aquella vida comunitaria que se proponía: ser un solo cuerpo, un fuerte signo de unidad, de potencia y de reconocimiento. Razón por la cual nunca fueron construidos en lugares fortuitos, más bien es observable que los dominicos, desde su primer arraigo en Europa hasta su llegada a Chiapas, demostraron una particular habilidad en el penetrar rápidamente la dimensión espacial de las sociedades humanas y saber sacar sus ventajas.

Para poderse acercar a los indios y persuadirlos de abrazar la fe en un nuevo Dios misericordioso, los frailes predicadores pensaron bien en evangelizar en las lenguas nativas. Gracias a las posiciones claves de los centros de población elegidos, los dominicos aprendieron las lenguas de mayor difusión en Chiapas; tzotzil, tzeltal, chiapaneca y zoque. Se elaboraron pequeños diccionarios, doctrinas y confesionarios en lenguas, para facilitar el trabajo pastoral. ${ }^{19}$ Debido a la pronta

${ }^{16}$ Fr. A. Remesal, Historia general de las Indias Occidentales y particular de la gobernación de Chiapa y Guatemala, I, p. 415, citado en Dolores Aramoni Calderón, Los Refugios de lo Sagrado, Consejo Nacional para la Cultura y las Artes, México (1992: 136).

${ }^{17}$ La palabra "convento" es usada en su acepción de sede de un priorato o de una vicaría.

${ }^{18}$ Este priorato fue trasladado en 1547 a Ciudad Real, un año después de su fundación.

${ }^{19}$ Parte de estas elaboraciones fueron publicadas por Mario Humberto Ruz en: Las 
cristianización de las élites indias, ${ }^{20}$ las autoridades locales fueron respetadas y prestigiadas por los naturales, así en poco tiempo los dominicos pudieron conquistar la confianza de buena parte de las poblaciones y lograr la expansión de la nueva fe en los centros más ricos de Chiapas (Viqueira 2002: 130-131). Los frailes predicadores pusieron nombre de santos a cada pueblo, construyeron iglesias, administraban sacramentos, organizaron mayordomías y cofradías, iniciaron fiestas de santos patrones y funciones ceremoniales útiles para promover una de las devociones más importantes para la espiritualidad dominica: la devoción a la Virgen María, que desde la fundación de la orden fue considerada un modelo educativo ideal para la divulgación de la fe católica.

El trabajo de evangelización no abarcó sólo el ámbito estrechamente religioso. Los dominicos desempeñaron un papel importante en la imposición de la corona española en Chiapas. En particular lograron obtener, con la presencia de jueces de comisión ${ }^{21}$ y del visitador de la Audiencia, la aplicación de las Leyes Nuevas. ${ }^{22}$ En 1549 los dominicos crearon un nuevo mapa territorial, trasladando y congregando en un mismo pueblo diferentes poblaciones indígenas, de diferente entidad sociopolítica y en algún caso de distintas lenguas y cultos religiosos. ${ }^{23}$ Como buenos arquitectos, los dominicos construyeron un verdadero espacio urbano, según Viqueira, de "inspiración renacentista" (Viqueira, 2002: 344). Su Ciudad del Sol propone separaciones y jerarquías, designa vida moral y política.

Lenguas de Chiapas Colonial. Manuscritos en la Biblioteca Nacional de París. Volumen Uno: Lenguas mayenses (1989a); Las Lenguas de Chiapas Colonial. Manuscritos en la Biblioteca Nacional de París. Volumen Dos: La lengua zoque (1997); y junto a C. M. Baez, Las Lenguas del Chiapas colonial. Volumen Tres: La Lengua chiapaneca (2004).

${ }^{20}$ Sin embargo a lo largo del tiempo, los frailes predicadores descubrieron el papel central que esta misma élite tuvo en el seguimiento de las prácticas religiosas de los naturales, juzgadas idolátricas.

${ }^{21}$ En Chiapa la aplicación de las Leyes Nuevas se obtuvo bajo el juez visitador Gonzalo Hidalgo de Montemayor (Aramoni, 1992; De Vos, 2010).

22 La Leyes Nuevas, además de abolir la esclavitud de los indios y el sistema de encomiendas, impulsaron hacia una política de congregación de la población indígena en poblados.

${ }^{23}$ En los pueblos de indios, los naturales pudieron mantener diferenciadas y vivas sus identidades, aunque sí resulta difícil creer que no pusieran alguna resistencia. 
Lo primero dieron lugar a la iglesia, mayor o menor, conforme al número de vecinos. Junto a ella pusieron la casa del padre, delante de la iglesia una plaza muy grande, diferente del cementerio, enfrente la casa de regimiento o consejo, junto a ella la cárcel y allí cerca el mesón o casa de comunidad, donde posasen los forasteros. Todo lo demás del pueblo se dividía por cordel, las calles derechas y anchas, norte a sur, este, oeste, en forma de cuadra (Remesal). ${ }^{24}$

Se enfrentaron así las dificultades de control político, económico y de evangelización de los indios, ligadas a la dislocación de las poblaciones originarias. En estos pueblos indios no se permitía entrar a los españoles ni a los mestizos ni los negros; de esta manera los frailes dominicos tenían el control de todo: pago de tributos, división de herencia y de todo tipo de bienes.

Los frailes, a lo largo de su historia de evangelizadores, evolucionaron hasta cambiar la que fue su vocación misionera: la evangelización de los indios y su conquista espiritual por medio de la persuasión pacífica. A su llegada a Chiapas los dominicos tenían experiencia de la labor evangelizadora en la Europa medieval, y de su labor misionera empezada en 1526 en México (Ulloa, 1977: 96). A pesar de eso las dificultades no tardaron en sobresalir. La escasez y las pestilencias alcanzaron también a los dominicos de Chiapas.

A partir de ese momento descubrieron las idolatrías de los naturales, las creencias prehispánicas hibridadas con creencias católicas que continuaban en cerros, cuevas y ríos. ${ }^{25}$ Impusieron una política del miedo, estrategia utilizada por la Iglesia desde la época medieval

${ }^{24} \mathrm{Fr}$. A. Remesal, Historia general de las Indias Occidentales y particular de la gobernación de Chiapa y Guatemala, libro VIII, cap. I, vol. II, p. 243.it, citado en J.P. Viqueira, "Las identidades colectivas en Los Altos de Chiapas", p. 344, en Encrucijadas chiapanecas. Economia, religión e identidades, Tusquets editores/El Colegio de México, México (2002: 334-374).

${ }^{25} \mathrm{Al}$ respecto Dolores Aramoni, en Los Refugios de lo Sagrado, nos introduce sapientemente en los términos de organización y realización de los juicios contra los indios denunciados por idolatría. También destaca las marcas de interpretación de los indios sobre la enseñanza cristiana y la continuidad de la religiosidad prehispánica. 
y seguida por la orden dominica en su tarea de evangelización de Chiapas, y buscaron introducir en el sentido común de los indios conceptos como la salvación eterna y la caracterización de la figura demoniaca. ${ }^{26}$ Para hacer frente a sus concretas exigencias, olvidándose de la observancia de la caridad, los hermanos predicadores empezaron a cobrar por misas, por administración de sacramentos, a asegurarse donaciones, a apropiarse de tierras y estancias. ${ }^{27}$ En la obra de evangelización de Chiapas, la aspiración de los dominicos de crear una comunidad incorrupta por el mal, que viviera según la caridad y que antepusiera como prioridad el amor al prójimo, cambió en un tipo de amor dictado por el egoísmo individual y la defensa de la misma vida terrenal.

Si bien haría falta un estudio sistemático y agudo de las fuentes primarias que podrían llenar los huecos y reconstruir en términos prácticos la labor evangelizadora de Chiapas y lo que significó, ${ }^{28}$ podríamos interpretar la congregación de pueblos indios como una obligación agresiva y simbólicamente violenta que implicó una transformación forzada de las geografías humanas, de las relaciones sociales que conllevan y la sobreexplotación de la población nativa, agravada por las mortales proliferaciones de enfermedades epidémicas (Viqueira, 2004: 106-108).

En un largo cuento de M. H. Ruz, una maravilla en la que haciendo hablar a la memoria de un río como un viejo y fatigado abuelo, el Río Grande, éste recuerda y narra:

\footnotetext{
${ }^{26}$ Para una amplia consideración sobre el tema específico y para comprender más las circunstancias de la diócesis de Chiapa, véase la reconstrucción propuesta por María del Carmen León Cazares en La Presencia del demonio en las Constituciones Diocesanas de Fray Francisco Núñez de La Vega (1993).

${ }^{27}$ La disposición tridentina De los regulares y monjas, contenida en la sesión XXV, permitió a las órdenes mendicantes de poseer, sólo en forma colectiva, bienes. Ver: El sacrosanto y ecuménico Concilio de Trento (1785) capítulos II, III y XXII, con textos de los decretos en original y traducción al español por Ignacio López de Ayala.

${ }^{28}$ Estudio que podrá ser facilitado gracias al trabajo, dirigido por Juan Pedro Viqueira, de ordenamiento del Fondo Diocesano del Archivo Histórico Diocesano de San Cristóbal de Las Casas.
} 
[...] Los dominicos, ya dueños del antiguo valle de Nejundilo y algunos de los de Llanos se dedicaron a levantar sus haciendas. Cómo cambian las cosas. Bien recuerda que eran frailes de la misma orden los que promovieron la libertad de los indios esclavos, y un siglo después obligaban a los naturales a trabajar para ellos, en tierras cada vez más extensas. Por algo quedó el nombrecito de La Frailesca. Ni se lo hubiera imaginado fray Bartolomé (Ruz, 2004: 53).

\section{Amor como apetito}

Como hemos sustentado anteriormente, la orden dominica, así como muchas de las órdenes mendicantes medievales, fundamentó su regla en la regla agustina. Toda la obra de San Agustín debe ser interpretada considerando sus dos mundos de pertenencia: el mundo helénico que lo impulsa siempre a la interrogación filosófica, y el mundo cristiano que lo orienta hacia las cartas paulinas y a los salmos.

Hannah Arendt analizó la riqueza y complejidad de la obra agustina, ${ }^{29}$ profundizando en el concepto de amor contenido en ella, entendido como appetitus, apetito, única definición que el Santo dio del amor. Hay que subrayar que la autora en todo su estudio presenta el amor siempre como fenómeno de existencia temporal. Es en la primera parte donde se describe sutilmente el sentimiento amoroso visto como inclinación, deseo de algo.

El amor en San Agustín representa la posibilidad de poder poseer lo deseado. El apetito, núcleo primordial del amor, consiste en este estado de inquietud del ser humano empujado por el deseo a poseer, una fuerza que lo mueve hacia algo alcanzable, pero una vez alcanzado queda comprometido por el riesgo de ser perdido. Arendt nos ofrece una lectura del amor agustino como un apetito comprendido entre el deseo de vida y el miedo de la muerte.

El viviente sometido a la corrupción y a la codicia muere en el miedo de no alcanzar nunca el objeto del deseo propio o de perder lo que se

${ }^{29}$ Análisis presentado como tesis en la Universidad de Heidelberg en 1928 y publicado en 1929 por la editorial Springer de Berlín bajo el título: Der Liebersbegriff bei Augustin (El concepto de amor en San Agustín). 
ama. Solamente una vida sin muerte no tiene miedo. El bonum, bien, del amor es para Agustín sólo lo que no se puede perder (Arendt, 2004:). Hay, por lo tanto, una distinción entre mundanidad - temporal- y eternidad — utopía — que lleva el Santo a distinguir dos tipos de amor: el cupiditas, codicia, temporal, el falso amor ese que se agarra al mundo; y el caritas, caridad, utópico o amor justo, que aspira a la eternidad. Un análisis que demuestra la posibilidad para el hombre de llenar el apetito sólo si este último está dirigido hacia aquel Dios que es vida eterna. Solamente el hombre que quiere en la caridad existe en la eternidad, perdiendo la mortalidad que caracteriza el amor codicia.

Según el pensamiento agustiniano y por efecto en la doctrina de la Iglesia católica, ${ }^{30}$ la primera disposición del ser viviente al amor caridad está relacionada con la acción de la escucha. Dios llama por nombre a Abraham y a él dirige la palabra, su manifestación es sólo voz, sonido; Abraham es un hombre que sólo escucha la palabra de Dios, dejándose remodelar en una nueva creación. Cuando el individuo se abre a la escucha de Dios, eligiendo vivir según el amor caritas, realiza plenamente el encuentro profundo con Cristo. "Todo aquel que ama, es nacido de Dios, y conoce a Dios. El que no ama, no ha conocido a Dios; porque Dios es amor" (1Jn 4, 7-8). El encuentro con Dios, encuentro con el amor, asume un carácter particular en el sentido de que establece una alianza. Con la elección del amor caridad de Dios el ser en su condición de individuo, atrapado en la soledad y en el egoísmo del amor codicia, un amor agotado por el afán, se eleva a la condición de hombre criatura de Dios que se abre al otro en una relación de comunión y alianza. El hombre que habita en el amor de Dios se convierte en lugar habitado por el amor caritas de Dios, un amor puro, sin mancha. "Dios es amor; y el que permanece en amor, permanece en Dios, y Dios en él” (1Jn 4,16).

Este concepto central del pensamiento cristiano pone el acento en el amor/Dios, realidad en la cual permanecer. Jesús primero permaneció

${ }^{30}$ En las enseñanzas y en la interpretación bíblica de Agustín de Hipona radica y se construye la doctrina de la iglesia católica. Conjunto de escritos que le hicieron merecer el título de Doctor y Padre de la iglesia. También H. Arendt en su libro La vida del espíritu (2002) afirma que a Agustín de Hipona se debe la transformación de la fe cristiana en religión. 
en la cruz sin miedo a la muerte, permaneció en Dios, analogía del amor/caridad, y en esta permanencia derrotó la muerte/amor codicia. El amor caritas de Jesús que se somete a una muerte en la cruz restablece una nueva alianza entre Dios y su pueblo, "porque fuerte es como la Muerte el Amor" (Cnt 8,6) es el canto que se proclama en el capítulo octavo del libro bíblico Cantar de los Cantares. La muerte y resurrección de Jesús restablece la filiación divina del pueblo de Dios. Como Hijos del Dios, ab aeterno e in eternum, desde siempre y para siempre, el pueblo recibe en herencia la eternidad de la vida. "Así como Cristo fue resucitado de entre los muertos por la Gloria del Padre, así también nosotros empezamos una vida nueva” ( $\mathrm{Rm} 6,4)$. Se trata de una resurrección que se refiere no sólo al alma sino también al cuerpo. El Dios de la resurrección "no es un Dios de muertos, sino de vivos" (Mc 12, 27). El concepto de la resurrección de los hombres en alma y cuerpo es una consecuencia intrínseca fuertemente vinculada al tema de Dios creador del hombre, creador de su cuerpo y de su alma. En la doble naturaleza de Jesús, humana y divina, reposa para la tradición cristiana la doble realidad del hombre, de su cuerpo y de su alma.

Convencido de que el hombre está compuesto por alma y cuerpo, Agustín lee la necesidad de atender los apetitos de la carne como una caída del hombre en la corrupción, en el pecado. Con la desobediencia de Adán el hombre reconoce su cuerpo desnudo, es decir, con el pecado ocurre la separación del alma y el cuerpo, y la muerte entra en el hombre. Así que el amor se vuelve cupiditas, codicia, o caritas, caridad, según lo que le da apetito. Solo la sumisión del cuerpo al espíritu, la crucifixión de mi deseo terreno, alcanzable por medio de la permanencia del hombre en el amor caritas de Dios, permite la superación de la muerte. "Lo que tú siembras debe morir para recobrar la vida" (1Co 15, 36); asimismo en la comunión con el amor caritas de Dios el hombre viejo muere para resurgir a la vida en el hombre nuevo, restituido en un cuerpo incorruptible (1 Co 15, 42-43).

El tema central que siempre se reitera es el de la comunión con Dios. “Todos mueren por estar incluidos en Adán, y todos también recibirán la vida en Cristo" (1Co 15, 22). Los hombres que aman con amor caritas permanecen en Dios y uno en los otros, renuncian 
al individualismo del falso amor, que conduce a la muerte, para ser en común-unión con Dios (Ro 8, 11). La muerte es la que delinea el confín entre el amor para las riquezas temporales y las riquezas eternas, únicas incorruptibles. Si consideramos que la fundación de una comunidad es un asunto contiguo al asunto de la muerte - por ejemplo la misma comunidad cristiana nació con la muerte de Jesús crucificado, en la comunión/koinonia los cristianos recuerdan y reciben su cuerpo, ofrecido en sacrificio-, valorizaremos el aspecto de la deuda en el don. El don (munus) es lo que establece una deuda, pues crea obligaciones entre sujetos deudores y sujetos acreedores. Se puede decir que cada comunidad nace a partir de una obligación que une un grupo de personas y que los convierte en personas no plenamente dueñas de sí mismas. Lo que tiene en comunión una sociedad es el debido contrato (Esposito, 2006). No se trata de una relación de poder entre la voluntad del dominante que se apodera de la voluntad del dominado. Más bien, se pueden hablar en términos de mediación así como lo propone José Luis Escalona (2001) respecto a un análisis de las interacciones entre Estado nacional y contextos periféricos. Es decir, la actividad evangelizadora de los dominicos en Chiapas podría verse como un "espacio de interacción entre poblaciones, tanto en el contexto del culto religioso, como en el comercio y la comunicación en general" (Escalona 2001: 64). Incluso, con significado contradictorio y utópico entre las heterogéneas relaciones de poder.

Por una parte, los frailes predicadores ofreciendo su protección a los oprimidos, según la ley ideal de la primera comunidad fundada en el amor, dieron vida a mediaciones basadas en el intercambio desigual; a cambio de la protección y la evangelización, los nativos dieron fidelidad (Matheson, 1987), reproponiendo una característica de la relación de poder señor-vasallo (Baschet 2009) que genera un amplio abanico de relaciones de poder: político, de propiedad, de apropiación de tierras y de almas (Escalona, 2009). Una acción evangelizadora en el sentido de encrucijada de mediaciones delicadas y dinámicas entre indios y dominicos, así como de indios y autoridades civiles.

Por otra parte, los diferentes aspectos de la evangelización de Chiapas se configuran como el punto heterotópico de encuentro entre tres 
utopías: la del mito cristiano del paraíso, la del mito de la ciudad ideal griega — La República de Platón—y la del mito popular del País de la Jauja, un lugar abundante de riqueza y comida donde no es necesario trabajar. Hay que tener en cuenta que la orden de los hermanos predicadores es medieval, entonces como marca de continuidad de este siglo retornan a la antigüedad inaugurándola en un nuevo comienzo. La utopía de un nuevo comienzo, según el modelo de la antigua y primera comunidad cristiana, a la larga enmascaró diversos mecanismos de apetitos codiciosos; la promesa de una Ciudad del Sol se convirtió en distopía, en la cual la voracidad fue el motor o impulso.

\section{Reflexión final}

Tal vez de forma imperceptible, como sucede siempre en las historias particulares, también la orden dominica empezó el abandono de aquel amor caritativo fundado en el principio simple de la condición salvífica del amor de Dios para abandonarse al desvío de un amor codicioso que mira al prójimo ahora como ser humano perverso. La índole humana constituida por una doble naturaleza es habitada por dos tipos de amores: amor caridad y amor codicia, en ella se entrelazan sin poderse separar y conviven alternando la supremacía del uno sobre el otro.

En el espacio íntimo de la inclinación del abandono reside la calidad del amor. En poco tiempo la historia de corrupción que aflige la condición humana se repite; el apetito caritas de los dominicos cedió su lugar al apetito cupiditas. El poder económico de los dominicos creció y se consolidó constantemente. Los frailes convertidos en principales terratenientes controlaron todo el territorio chiapaneco (Viqueira 2002: 131-134), detentando un papel de conditio sine qua non en la introducción de las instituciones políticas y religiosas españolas. Pareció como si todo lo malo del viejo mundo, corrupción, idolatría, guerras, pestes, hubiera alcanzado la vida nueva de aquellos hombres que huyeron de esta misma podredumbre. El recuerdo de los frailes predicadores anunciadores de la buena nueva, comprometidos con la defensa de los naturales oprimidos, se desvaneció. El sueño de una ciudad celeste murió para dar lugar a una nueva ciudad terrenal habitada por hombres sin dilectio proximi, amor al prójimo. Los 
frailes dominicos en lugar de abandonarse a la caridad, abandonan la caridad.

En los hombres mendicantes, que por su regla hubieran debido vivir de y por el amor caritas, reconocemos la fragilidad del hombre normal, o mejor decir del hombre ordinario, víctima de su misma doble naturaleza, divina y malvada. Y si en el pensamiento filosóficoteológico el reino de Dios está en el hombre (Lucas 17, 21), también el mal, "porque la intención del corazón del hombre es mala desde su juventud" (Génesis 8, 21). Los dominicos, hombres entre los hombres, se abandonaron al mísero apetito de lo temporal hecho de miedo, soledad, soberbia, traiciones, dolor, de agresión y violando su predicación, abandonaron los significados y las promesas de fidelidad a su misma regla de vida. Eso quiere decir que en la condición humana hay una constante tensión que se discute entre lo malvado, que es dolorosamente estéril, y la caridad que es instinto a la vida. La caritas voz tierna, llena de armonía que dice y exhorta al hombre de ayer como de hoy: "vives todavía. Yo soy la vida. En mis ojos está tu cielo. Tú no estás solo. Tus lágrimas yo las protejo. Estoy en tu camino y te socorro. Sonríe y espera. Yo soy el amor. ¿Alrededor todo es sangre y fango? Yo soy divino, soy el olvido. Soy el Dios que predomina el mundo, desciende de las alturas y hace de la tierra un cielo. Vives todavía! Yo soy el amor" ${ }^{31}$

\section{Bibliografía citada}

Alighieri, Dante, 2007, La divina commedia, Mondadori, Milano. Aquino, Tomás de, 1970, Summa theologiae, vol. XXV, Salani, Roma. Aquino, Tomás de, 1994, Suma de Teología. Edición dirigida por los Regentes de Estudios de las Provincias Dominicas en España, 5 vols., Biblioteca de Autores Cristianos, Madrid.

Aramoni Calderón, Dolores, 1992, Los refugios de lo sagrado. Religiosidad, conflicto y resistencia entre los zoques de Chiapas, Consejo Nacional para la Cultura y las Artes, México.

${ }^{31}$ Traducción propia de la célebre aria "La mamma morta" de la ópera Andrea Chénier de Umberto Giordano con libreto de Luigi Illica. Recomiendo la preciosa interpretación de María Callas en el Teatro alla Scala de Milán, director de orquesta Antonino Votto. 
Arendt, Hannah, 2002, La vida del espíritu, Paidós, Barcelona.

Arendt, Hannah, 2004, Il Concetto d'Amore in Agostino, Se SRL, Milano. Biblia de Jerusalén Mod.2, 1991, Traducción realizada por la Escuela Bíblica de Jerusalén, Alfredo Ortells, S. L., Valencia.

Baschet, Jérôme, 2009, La civilización feudal. Europa del año mil a la colonización de América, FCE, México D.F.

Campanella, Tommaso, 1997, La città del Sole, Laterza, Roma-Bari.

Catapano, Giovanni, 2008, "Hannah Arendt e Hans Jonas interpreti del concetto agostiniano di volontà”, en Etica \& Politica/Ethics \& Politics, vol. X, núm. 1, pp. 12-27.

De Vos, Jan, 1988, La paz de Dios y del Rey. La conquista de la Selva Lacandona (1525-1821), FCE, México.

De Vos, Jan, 1994, Vivir en frontera. La experiencia de los indios de Chiapas, CIESAS, México.

De Vos, Jan, 2010, Fray Pedro Lorenzo de la Nada. Misionero de Chiapas y Tabasco, FCE, CIESAS, México.

Douie, Decima Langworthy, 1954, The conflict between the seculars and the mendicants at the University of Paris in the thirteenth century. A paper read to the Aquinas Society of London on 22nd June, 1949, Langworthy, London.

El sacrosanto y ecuménico Concilio de Trento, 1785, Traducido al idioma castellano por Ignacio López de Ayala. Agregase el texto latino corregido según la edición auténtica de Roma, publicada en 1564 (segunda edición), Imprenta Real, Madrid, pp. 480-515. Escalona Victoria, José Luis, 2001, "Pluralismo y mediaciones: imaginario sociopolítico en Chiapas”, en Salvador Maldonado (editor), Dilemas del Estado nacional, El Colegio de Michoacán, México, pp. 55-76.

Escalona Victoria, José Luis, 2009, "Para una antropología del poder. Una agenda a partir de trabajos recientes sobre la finca y la comunidad en Chiapas", en Anuario del Instituto de Estudios Indigenas de Unach, T. V, XIII, México, pp. 15-52.

Esposito, Roberto, 2006, Communitas. Origine e destino delle comunità, Piccola Biblioteca Einaudi, Torino. 
Gerhard, Peter, 1991, La Frontera sureste de la Nueva España, Universidad Nacional Autónoma de México, México D.F.

González Fuente, Antolín O.P., 1994, El carisma de la vida dominicana, Editorial San Esteban, Salamanca.

Hipona, Agustín de, 1973, De Trinitate. Città Nuova, Roma.

Hipona, Agustín de, 1994, La Ciudad de Dios (XII Ed.), Editorial Porrúa, S.A., México.

Hipona, Agustín de, 1995, "Regula ad servos Dei”, en Teodoro Calvo Madrid (compilador), Obras completas de San Agustín, Tomo XL, Bibliotecas de Autores Cristianos, Madrid, pp. 531-591.

Hipona, Agustín de, 2002, Comentario a la primera carta de San Juan, Ediciones Sígueme, Salamanca.

Jedin, Hubert, 1967, Riforma cattolica o Controriforma?, Morcelliana, Brescia.

León Cazares, María del Carmen, 1993, "La presencia del demonio en las constituciones diocesanas de Fray Francisco Núnez de La Vega", en Estudios de Historia Novohispana, vol. 13, Instituto de Investigaciones Históricas, UNAM, México, pp. 41-71.

Matheson, Craig, 1987, "Weber and the Classification of Forms of Legitimacy", en The British Journal of Sociology, vol. 38, núm. 2, Jun., pp. 199-215.

Platón, 1989, La República, Juventud, Madrid.

Remesal, Antonio de, 1988, Historia general de las Indias Occidentales y Particular de la Gobernación de Chiapa y Guatemala, Editorial Porrúa, S. A, México, D. F.

Rotterdam, Erasmo de, 1842, Elogio de la Locura, Imprenta de José Tauló, Barcelona.

Rubial García, Antonio, 1989, El convento Agustino y la sociedad novohispana (1533-1630), UNAM, México, D.F.

Ruz Sosa, Mario H., 1989a, Las lenguas del Chiapas colonial. Manuscritos de la Biblioteca Nacional de Paris. vol.1: lenguas mayanses (tojolab'al, cabil, mochó, tzotzil y tzeltal), versión paleográfica, introducción y notas de M.H. Ruz, CEM, IIF, UNAM, México (Serie Fuentes para el estudio de la cultura maya núm. 7). 
Ruz Sosa, Mario H., 1989b, Chiapas Colonial: dos esbozos documentales, UNAM, México, D.F.

Ruz Sosa, Mario H., 1992, Savia india, floración ladina. Apuntes para una historia de las fincas comitecas (siglo XVIII y XIX), Consejo Nacional para las Culturas y las Artes, México, D.F.

Ruz Sosa, Mario H., 1997, Las lenguas del Chiapas colonial. Manuscritos de la Biblioteca Nacional de París. vol. 2, La lengua zoque, versión paleográfica, introducción y notas de M.H. Ruz, Seminario de Lenguas Indígenas, IIF, UNAM, México.

Ruz Sosa, Mario H., 2004, "Memorias del Río Grande”, en J.P. Viqueira y M.H. Ruz (editores). Chiapas. Los rumbos de otra historia, Instituto de Investigaciones Filológicas/Centro de Estudios Mayas UNAM, Centro de Investigaciones y Estudios Superiores en Antropología Social, México, D.F., pp. 43-70.

Ruz Sosa, Mario H. y C. M. Baez, 2004, Las lenguas del Chiapas colonial, vol. III: La lengua chiapaneca, UNAM, Instituto de Investigaciones Filológicas, México.

Ulloa, Daniel, 1977, Los Predicadores divididos. Los dominicos en Nueva España, siglo XVI, El Colegio de México, México, D.F.

Viqueira Albán, Juan Pedro, 2002, Encrucijadas Chiapanecas. Historia, economí, religión e identidades, Tusquets Editores, El Colegio de México, México, D.F.

Viqueira Albán, Juan Pedro, 2004, "Las causas de una rebelión india: Chiapas, 1712", en J.P. Viqueira y M.H. Ruz (editores), Chiapas. Los rumbos de otra historia, Instituto de Investigaciones Filológicas/Centro de Estudios Mayas UNAM, Centro de Investigaciones y Estudios Superiores en Antropología Social, México, D.F., pp. 103- 143.

Viqueira Albán, Juan Pedro (dir.), 201, Base de datos del catálogo del Fondo Diocesano del Archivo Histórico Diocesano de San Cristóbal de Las Casas, Primera parte (Carpetas 1 a 466), El Colegio de México, México, D.F.

Viqueira Albán, Juan Pedro (dir.), 2013, Base de datos del catálogo del Fondo Diocesano del Archivo Histórico Diocesano de San Cristóbal de Las Casas, Segunda entrega, El Colegio de México, México, D.F. 
Ximénez, Francisco, 1999, Historia de la Provincia de San Vicente de Chiapa y Guatemala, de la Orden de Predicadores, 5 vols., Consejo Estatal para la Cultura y las Artes de Chiapas, Tuxtla Gutiérrez.

Documento histórico firmado publicado

Honorio III, 1896, Carta a Santo Domingo, fecha 18 de enero de 1221, Monumenta Ordinis fr. Praedicatorum Historica 35 vol., Istituto storico domenicano di Roma, Italia (144).

Cita de artículo en revista electrónica

Foucault, Michel. "Topologías”, Fractal, [en línea] 2008, (núm. 48) [fecha de consulta: 13 de octubre de 2013] Disponible en: http:// www.mxfractal.org/RevistaFractal48MichelFoucault.html

Cita de un trabajo en disco compacto

Giordano, Umberto. "La mamma morta". [Grabado por Maria Callas, Maddalena; Orquesta del Teatro alla Scala; Antonino Votto, director]. En Andrea Chérnier, [2 CD]. Live Recordings. Milán: Melodram, 1955. MEL26002. 